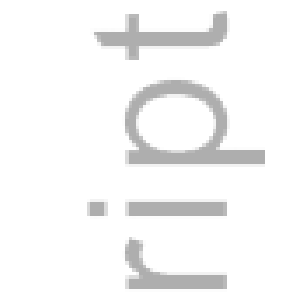

The role of students' motivation and participation in predicting performance in a MOOC

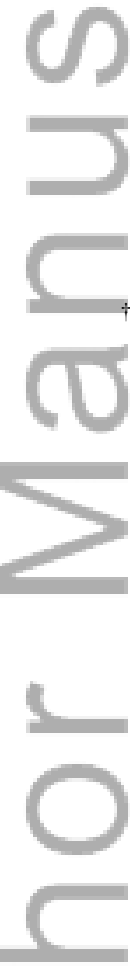

Cörrespondence: Paula G. de Barba, Centre for the Study of Higher Education, The University of Melbourne, Victoria 3010, Australia. Email: paula.de@unimelb.edu.au

P.G. de Barba, ${ }^{* \dagger}$ G.E. Kennedy ${ }^{*+}$ \& M.D. Ainley ${ }^{\dagger}$

*Centre for the Study of Higher Education, The University of Melbourne, Australia

Melbourne School of Psychological Sciences, The University of Melbourne, Australia

Learning Environments, The University of Melbourne, Australia

This is the author manuscript accepted for publication and has undergone full peer review but has not been through the copyediting, typesetting, pagination and proofreading process, which may lead to differences between this version and the Version of Record. Please cite this article as doi: $10.1111 /$ jcal.12130

This article is protected by copyright. All rights reserved. 


\title{
The role of students' motivation and participation in predicting performance in a MOOC
}

\begin{abstract}
Over the last five years, massive open online courses (MOOCs) have increasingly provided learning opportunities across the world in a variety of domains. As with many emerging educational technologies, why and how people come to MOOCs needs to be better understood, and importantly what factors contribute to learners' MOOC performance. It is known that online learning environments require greater levels of self-regulation, and that high levels of motivation are crucial to activate these skills. However, motivation is a complex construct and research on how it functions in MOOCs is still in its early stages. Research presented in this article investigated how motivation and participation influence students' performance in a MOOC, more specifically those students who persist to the end of the MOOC. Findings indicated that the strongest predictor of performance was participation, followed by motivation. Motivation influenced and was influenced by students' participation during the course. Moreover, situational interest played a crucial role in mediating the impact of general intrinsic motivation and participation on performance. The results are discussed in relation to how educators and designers of MOOCs can use knowledge emerging from motivational assessments and participation measures gleaned from learning analytics to tailor the design and delivery of courses.
\end{abstract}

Keywords: MOOC, learning analytics, motivation, participation, performance, persistence 


\section{Introduction}

Most researchers, practitioners and educators involved with educational technology would now be aware of the movement known as massive open online courses (MOOCs). Originating with George Siemens and Stephen Downes' Connectivism and Connective Knowledge course in 2008 (Daniel, 2012; Liyanagunawardena, Adams, \& Williams, 2013; Yuan \& Powell, 2013) MOOCs were originally designed on principles of connectivism (Siemens, 2005). The core pedagogical elements were peer-based learning in social networks, students' self-direction within a broad and often open-ended curriculum structure, a reliance on rich sources of freely available content on the Internet, and the use of technology-based tools to assist with resource aggregation. In a remarkably short period of time these so-called cMOOCs (as they were based on connectivist principles) were appropriated by mainstream higher education providers and with this came the birth of the xMOOCs. xMOOCs eschewed many of the fundamentals associated with the original cMOOCs (Daniel, 2012; Yuan \& Powell, 2013), but differed from other online offerings of a University as they were open to anyone in the world who was interested and had an Internet connection. xMOOC providers such as Udacity, edX and Coursera quickly emerged, and prestigious institutions from around the world raced to offer MOOCs on these platforms. The growth in these open courses worldwide has been remarkable; at the time of writing Coursera has 114 partners offering over 840 courses to over 9.9 million enrolled students.

As breathtaking as this advance is, it is important to recognise that many perennial questions about student learning online remain, despite the scale, international scope, and excitement surrounding MOOCs. For example, greater understanding is needed of why some students persist with a MOOC. Although initially MOOCs students are highly motivated, only a very small number persist until the end of the course (e.g., Clow, 2013; MOOCs@Edinburgh 
Group, 2013). Previous studies show that lack of persistence in online environments is associated with low levels of motivation (Hart, 2012; Vallerand, Fortier, \& Guay, 1997; Vanthournout, Gijbels, Coertjens, Donche, \& Van Petegem, 2012). However, not much is known about how this relationship functions in an environment where students are initially highly motivated, such as MOOCs. In this article we build on previous psychological and educational research and consider fundamental questions about the achievement motivation of students who persist in online learning environments, and in particular consider their motivation and participation when studying in a MOOC. As we will show in this article, considerable insight into these questions can be gained by combining traditional data collection methods with novel learning analytic techniques.

\section{Motivation}

Achievement motivation concerns the types of factors that lead to high performance in achievement situations (Nicholls, 1984). From a social cognitive perspective (e.g., Pintrich, 2000, 2003) motivation is composed of distinct but interacting constructs; systems of beliefs that have different patterns of activation depending on contextual and personal factors. Hence, motivation is a dynamic state, and while an individual can bring to a MOOC a strong general motivation for learning that tends remain stable over time, the MOOC context and content can alter or trigger changes in motivational states (state-level motivation). Five motivational constructs have featured prominently in recent research, namely, interest, achievement goals, value beliefs, self-efficacy, and control beliefs (Pintrich, 2003). In this study we investigated three of these constructs, interest, achievement goals, and value beliefs, often considered to be parts of the broad construct of intrinsic motivation and which together provide insight into 
students' purposes for engaging with different learning tasks (e.g., Eccles \& Wigfied, 2002; Hidi \& Harackiewicz, 2000; Wigfield \& Cambria, 2010).

The first of these constructs, interest, is generally approached from two perspectivesindividual and situational interest. Individual interest is a relatively stable predisposition that a person develops over time towards a particular topic or domain (Hidi \& Renninger, 2006; Renninger, 1990). It is what students bring to their learning experiences, and what influences their initial impulse to engage with a course. On the other hand, situational interest is a relatively transient state triggered and potentially maintained by the environment (Hidi, 1990; Hidi \& Renninger, 2006). So, even when a student does not have an existing individual interest towards a certain topic or domain, on entering the learning environment specific aspects of the environment such as novelty may trigger interest. However, in order for situational interest to support learning, it needs to be maintained (Ainley, 2006; Hidi \& Renninger, 2006). Hence, this study distinguished two forms of interest: individual interest as a component of the intrinsic motivation variable, and situational interest across the MOOC as a component of state-level motivation.

The second motivation construct is achievement goals, defined as the 'different ways of approaching, engaging in, and responding to achievement situations' (Ames, 1992, p. 261). This construct has been applied as a general orientation to learning and as the achievement goals with which a student approaches a particular course or learning task. Early studies generally compared the effects of either mastery or performance goals on students' achievement (Dweck, 1986; Nicholls, 1984). Mastery goals are a component of intrinsic motivation and are present when the learner's aim is to develop competence using self-reference standards, while the focus of performance goals is on demonstrating ability in comparison to others, that is, aiming to outperform them. A number of studies have linked mastery goals to positive outcomes and 
performance goals to maladaptive ones (i.e. using non-effective learning strategies; e.g., Pintrich, 2003). Further developments in achievement goal research emphasised the need to distinguish approach and avoidance tendencies within the major categories of mastery and performance goals resulting in a two-by-two classification (e.g., Elliot \& McGregor, 2001). More recently a multiple goals perspective has been adopted showing that students who adopt both masteryapproach and performance-approach goals simultaneously, achieve beneficial outcomes (Senko, Hulleman, \& Harachiewicz, 2011). However, across a variety of learning environments, masteryapproach goals consistently have been associated with positive learning outcomes (e.g., Belenky \& Nokes-Malach, 2012; McGregor \& Elliot, 2002), and therefore is the achievement goal construct that has been incorporated into the intrinsic motivation variable used in this study. The final motivation construct concerns value beliefs associated with a course or a task. Research into value beliefs in educational contexts commonly uses the expectancy-value theory (see Wigfield \& Eccles, 1992) and focuses on the reasons students believe an academic task is important to them. According to this theory task value beliefs have four components: attainment value or importance, intrinsic value or interest, utility value or usefulness, and cost. Attainment value is related to how important it is for a student to perform well on a task and how this expresses or confirms aspects of personal identity. Intrinsic value or interest is similar to the construct of individual interest considered above. Utility value concerns whether students' perceive the task or course being useful for other tasks or aspects of their lives. Finally, cost refers to the negative effects related to engaging in the task (Eccles, Wigfield, \& Schiefele, 1998; Wigfield \& Eccles, 2000). All of these components contribute in different ways to students' decision to either engage with learning activities or to withdraw. This study focused on utility value beliefs as it has been related to learning outcomes (see Hulleman, 2007 for a review), and it was included as a component of the intrinsic motivation variable. 
In sum, motivation is a complex concept, composed of a variety of constructs with different characteristics and functions. This study specifically investigated intrinsic motivation as a combination of individual interest, mastery-approach goals, and utility value beliefs representing students' general motivation for learning; and situational interest as students' statelevel motivation across the MOOC. A number of recent findings (e.g., Rotgans \& Schmidt, 2011) suggest that it is how motivational variables, such as situational interest, play out across a learning task, that may be associated with achievement through effects on participation in learning behaviours, which in turn are related to learning outcomes. Hence, in the current investigation we examine both direct effects of the motivation variables on course performance, and indirect effects where motivation may predict and be predicted by students' participation in course activities.

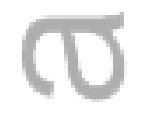

\section{Participation and motivation in online learning environments}

Although there is not a large body of research which has considered how key achievement motivation factors impact on students' participation and performance in online learning environments, there have been a couple of studies which are consistent with the proposition that motivation may influence outcomes indirectly through their influence on participation. In a study where participants were enrolled in an online distance course, Yang, Tsai, Kim, Cho, and Laffey (2006) found that as well as being positively correlated to performance in an online environment, value beliefs predicted social navigation, which is when other students' activities guide a student's navigation through the online environment. For example, the number of posts under topic headings influences students' recognition of importance of topics in an online discussion. Also using participants in an online distance course, 
Sun and Rueda (2012) investigated the relationship between motivation and engagement, and found that situational interest predicts behavioural, emotional and cognitive engagement.

Not surprisingly, substantive research into the operation of MOOCs is only just emerging (see Liyanagunawardena et al., 2013 for a review). Early research focused on questions considering student demographics, how many students were enrolling in MOOCs, the general reasons students were attracted to MOOCs and, often through the use of the learning analytics MOOC platforms produce, what are the kinds of activities students engaged in, and who persisted to the end of the course (see Breslow, Pritchard, DeBoer, Stump, Ho, \& Seaton, 2013; Christensen, Steinmetz, Alcorn, Bennett, Woods, \& Emanuel, 2013; MOOCs@Edinburgh Group, 2013;). These types of data have then been used in investigations that have related demographics variables (e.g., previous education, gender) to measures of MOOC participation (e.g., assignments completed; videos viewed, contribution to online discussions) and measures of performance (e.g., course completion or grades). For example, Rayyan, Seaton, Belcher, Pritchard, and Chuang (2013) considered how performance and retention on a Physics MOOC was related to participants' educational background. Other researchers, such as Kim, Guo, Seaton, Mitros, Gajos, and Miller (2014), are starting to focus on investigations of engagement with specific MOOC components. In their research, they conducted an in-depth investigation of students' behaviour while watching videos, such as watching the entire video, dropping out after a certain time, or re-watching only parts of it. Moreover, Milligan, Littlejohn, and Margaryan (2013) have shown the importance of motivation for MOOC engagement in their research. However, the relationship between MOOC participation behaviours as measured using learning analytics and motivation is yet to be better understood (Liyanagunawardena et al., 2013).

One of the major issues to be addressed in research examining the role of motivation in MOOC participation and performance is the development of measures that can be incorporated 
into course delivery at critical points thereby allowing some understanding of the dynamics linking motivation, participation and performance. In the current study we were restricted to administering the motivation questionnaire at the end of the course. Greater insight into the dynamics of the links between motivation, participation and performance will come when researchers are able to embed questions within the ongoing course materials. This will involve $=$ designing measures that record how learners are feeling and thinking about their learning as it is occurring. The challenge here is to have sound measures that are not intrusive and that do not interrupt the flow of course activities. Short scales and even single-item measures are being explored in this regard. For some time it has been argued that single items can be used to measure psychological constructs, such as motivation and job satisfaction, when the constructs are sufficiently narrow, clear and unambiguous (e.g., Ainley \& Patrick, 2006; Wanous, Reichers, \& Hudy, 1997). More recently, Gogol et al. (2014) investigated the reliability and validity of three-item and single-item measures in relation to scores on full scales used to measure academic anxiety and academic self-concept in secondary students. Three-item short forms yielded reliabilities within acceptable ranges and strong correlations with the full scale. Single-item scales functioned in a similar direction but had slightly lower reliabilities and correlations with the full scale. Interestingly, the correlations between the single-item measures and external criteria in the form of a range of student characteristics were similar to the coefficients obtained with the full scales. In the present study we use a three-item scale incorporating items reflecting three interrelated but distinguishable components of intrinsic motivation. We also explore how the three items function if treated as single-item scales each measuring a component of intrinsic motivation. 


\section{The present study}

In this context, the present study examined how persistent students' motivation and participation predicted their final performance in a MOOC. More specifically this study was guided by four research questions:

1. To what extent does motivation-intrinsic motivation and situational interest-

$=$ predict performance in a MOOC?

2. To what extent does participation, in the form of videos hits and quiz attempts, predict performance in a MOOC?

3. Is there evidence that the prediction of performance in a MOOC by intrinsic motivation is mediated by levels of course participation, and situational interest?

4. Is there evidence that the influence of participation on performance in a MOOC is mediated by state-level motivation during the course?

This study proposes a model based on previous research indicating that participation in a course is influenced by and influences motivation across the course, and that a combination of direct and indirect effects influences overall performance (Figure 1). General motivation for learning -intrinsic motivation incorporating individual interest, mastery-approach, and value components-influences an initial state-level motivation, that is, entering situational interest. Entering situational interest then influences participation, which in turn influences the level of maintained situational interest across the course. Finally, there are both direct and indirect paths linking these motivation and participation variables with performance.

[INSERT FIGURE 1 ABOUT HERE] 
Figure 1. Proposed model of the relationship between general motivation for learning (intrinsic motivation), state-level motivation, participation and performance.

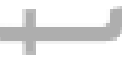

\section{Method}

\section{Participants and context}

Participants consisted of students who persisted to the last three weeks of the Principles of Macroeconomics MOOC, offered by The University of Melbourne in partnership with Coursera, and who voluntary elected to participate in the study. The introductory course in Macroeconomics was delivered over eight weeks, using a fairly traditional course design as is typical of many recent xMOOCs (Littlejohn, 2013). Each week students were given access to a number of short video lectures, and were asked to complete either practice quizzes (Weeks 1, 2, 4, 6, and 7), or graded quizzes (Weeks 3, 5 and 8). In addition, students completed a 1,500-word essay on a current topic in macroeconomics. Peer assessment of the essays was based on each student reviewing and grading three other students' essays. Students' peer assessment grades, together with graded quizzes, contributed to their final grade in the course. A discussion forum and social networking sites were used to provide additional avenues for interaction among students. Participants who achieved a final grade above 50 received a Statement of Accomplishment. Those who achieved a final grade above 80 received a Statement of Accomplishment with Distinction.

In the final week of the course, all 49,595 students who had expressed an interest in the course received an invitation via the announcement page on the Coursera site to participate in this research study. Of those who expressed interested in the course, 64.0\% $(n=31,741) \operatorname{logged}$ in during the first week and $14.1 \%(n=7,005)$ persisted in the form of interacting with either 
content or assessment during the last three weeks of the course. Students willing to participate clicked on a link to complete an online questionnaire.

A total of 862 students of those who were active over the last three weeks completed the questionnaire (age: $M=38.13, S D=16.34 ; 73.2 \%$ male). Over half of these participants had little prior knowledge in Macroeconomics (55.1\%), while others either informally knew advanced concepts such as economic growth and inflation (28.9\%), had a basic degree (13.7\%), or were specialists $(2.3 \%)$ in this field. More than two-thirds of the participants had either a Masters (38.9\%) or Bachelors (30.7\%) degree. Participants were from a range of countries including the United States of America (19.4\%), India (7.7\%), Australia (6.3\%), Spain (5.8\%), and Brazil (4.6\%), and most were fluent in English or native speakers (86.9\%).

\section{Measures}

Motivation. Motivational variables were assessed using a set of items adapted from scales used in previous motivation research (Elliot \& McGregor, 2001; Hulleman, 2007; Pintrich, Smith, Garcia, \& McKeachie, 1991). When factored, the responses from a previous laboratory study of motivation and online learning with undergraduate students (de Barba, 2015), indicated a strong intrinsic motivation factor that included items indicative of individual interest, masteryapproach goals and value beliefs. Using Cronbach's alpha coefficients and correlations between items and the total scale scores, three items were selected as a measure of intrinsic motivation and each item represented one of the three components of individual interest, mastery-approach goals and value beliefs. The resulting three-item scale had an internal consistency reliability coefficient (Cronbach's $\alpha$ ) of .85 in the previous laboratory study. When factored together the three items indicated a general factor accounting for $77.84 \%$ of the variance. The individual interest item ('I've always been fascinated by macroeconomics'), mastery-approach goals item 
('I wanted to learn as much as possible from this course'), and the utility value belief item ('I found the content of this course to be personally meaningful') used a 7-point Likert rating scale from 1 (Not at all true of me) to 7 (Very true of me).

Two state-level motivation constructs were measured: entering and maintaining situational interest. Items were adapted from a previous research (Harackiewicz, Durik, Barron, Linnenbrink-Garcia, \& Tauer, 2008), and have been used in a previous laboratory study indicating acceptable internal consistency (Cronbach's $\alpha$ entering situational interest: .78, Cronbach's $\alpha$ maintained situational interest: .82). Entering situational interest was measured using two items ('I thought this course was going to be interesting when I started', 'I was excited when I started this course'), and three items were used to measure maintaining situational interest ('Time went by really fast during the course', 'I had no problem in maintaining my interest level during this course', 'I enjoyed this course'). Summed scores produced an entering situational interest scale and a maintaining situational interest scale.

Participation. Learning analytics from the Coursera system were used to measure students' participation in the online course. Two types of learning behaviour were measured: video hits and quiz attempts. These behaviours were chosen as indices of 'course participation' as they are the most common and widely used components of a MOOC. Video hits was measured as the total number of clicks on lecture videos. Each week participants had access to several videos that could be viewed an unlimited number of times. In total, the course provided 49 videos, with durations between 6 and 31 minutes. Video hits could mean different behaviours, such as watching the entire video, dropping out after a certain time, or re-watching only certain parts (Kim et al., 2014). In this research, video hits were conceptualised as the intention to watch a video. Further analysis goes beyond the scope of this article. It is also important to note that 
there was no auto-play of videos in this course. For this sample, the sum of total number of video hits across the course varied from 0 to 359 .

Number of quiz attempts measured the number of times each participant submitted quiz responses. Each week participants were asked to complete one quiz, which consisted of a group of non-compulsory multiple-choice questions. One quiz attempt was considered a single submission of answers for at least one of the multiple-choice questions. As mentioned previously, quizzes were either practice (formative) or graded (summative). Practice quizzes had a limit of 100 attempts per student, with no deadline. Graded quizzes had a deadline, and there was a restriction of number of attempts before the deadline: three attempts for graded quizzes on weeks 3 and 5, and two attempts for the graded quiz on week 8. After the deadline, participants were able to have unlimited attempts for graded quizzes, but their new score was not considered for their final grade. For this sample, the total number of quiz attempts across the course varied from 0 to 50 .

Performance. The measure of performance was each participant's final grade, which ranged from 0 to 100 . Final grade was calculated as the mean score of the three graded quizzes and the peer-assessed essay.

\section{Procedure}

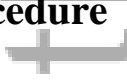

In the final announcement of their last week, students from the Principles of Macroeconomics MOOC were invited to voluntarily complete an online questionnaire. The online questionnaire included 11 demographic items including age, gender, employment status, education level, prior experience with MOOCs, English proficiency, country of residence, and background knowledge in Macroeconomics. In addition, there were items on students' perceptions of their overall experience with the course, hours per week spent with the course, 
and the eight motivation items. Although retrospective measures are not ideal for state-level motivation constructs, this study was considered a good opportunity to undertake preliminary research on motivation and MOOCs. The online questionnaire was administered through the Coursera platform using the quiz tool. Both online questionnaire and participation data, such as video hits and number of quiz attempts, were retrieved from the Coursera platform in commaseparated values format and analysed using SPSS version 22 and AMOS version 21.

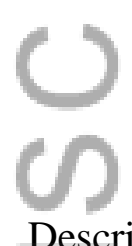

\section{Results}

Descriptive statistics presented in Table 1 showed that participants broadly presented high scores for intrinsic motivation and situational interest, with a negative skew. Moreover, participants had a mean of video hits higher than the number of videos released, indicating that participants were clicking on videos multiples times. A similar pattern was found for quiz attempts, with a higher average number of quiz attempts than the number of quizzes available. In addition, these variables presented a strong positive skew. For their final grade, participants had an average higher than 50, which was the threshold to receive the Statement of Completion. In all, 37.1\% $(n=320)$ of the participants received the Statement of Accomplishment and 39.9\% ( $n$ = 344) received the Statement of Accomplishment with Distinction.

Of all students who were still active in the last three weeks of the course, a comparative analysis presented clear differences between those who completed the survey $(n=862)$ and those who did not $(n=6,143)$. Those who completed the survey generally had higher levels of participation (video hits, Mann-Whitney $U=1189565.0, Z=-26.82, p<.0001$; quiz attempts, Mann-Whitney $\mathrm{U}=714104.0, Z=-37.89, p<.0001$ ), and performance (Mann-Whitney $U=$ $613481.5, Z=-43.08, p<.0001)$ than non-respondents. 
Reliability of the three motivational scales varied (Table 1). Maintained situational interest scale presented an acceptable reliability $(\alpha=.72)$, while entering situational interest scale presented a low reliability $(\alpha=.48)$. While it is desirable to have immediate measures of statelevel constructs, the current context did not allow it and so, the measure of entering situational interest was administered at the end of the course. Hence, it is likely this measure may have been affected in a variety of ways by students' actual course experience. Because of this low reliability the entering situational interest was not included in the analysis. The intrinsic motivation scale also presented a low reliability $(\alpha=.47)$. However, this scale was included as a measure of general motivation for learning and included items measuring three related constructs (individual interest, mastery approach and value beliefs). It was retained in the model testing which was repeated for two forms: as one three-item measure of intrinsic motivation, and as a three separate one-item measures of the intrinsic motivation components: individual interest, mastery approach, and value beliefs. As can be seen from Table 1 the total intrinsic motivation score was strongly correlated with individual interest and mastery approach and less strongly correlated with value beliefs.

Table 1. Descriptive statistics and Spearman correlations for all variables $(n=862)$

\begin{tabular}{lccccccccc}
\hline & 1 & $1 . a$ & $1 . b$ & $1 . c$ & 2 & 3 & 4 & 5 & 6 \\
\hline 1. Intrinsic motivation & $.77^{* *}$ & $.66^{* *}$ & $.68^{* *}$ & $.45^{* *}$ & $.53^{* *}$ & .05 & .06 & $.09^{* *}$ \\
1a. Individual interest & & $.26^{* *}$ & $.23^{* *}$ & $.35^{* *}$ & $.29^{* *}$ & -.02 & .02 & -.03 \\
1b. Mastery approach & & & $.41^{* *}$ & $.41^{* *}$ & $.40^{* *}$ & .02 & $.07 *$ & $.12^{* *}$ \\
1c. Value beliefs & & & & & & & & & \\
\end{tabular}


2. Entering SI

3. Maintained SI

4. Video hits

5. Quiz attempts

6. Final grade $\begin{array}{llll}.36 * * & -.03 & .03 & .05\end{array}$

$.15 * * \quad .08 * \quad .16 * *$

$.11 * * \quad .17 * *$

$.45 * *$

\begin{tabular}{lccccccccc}
\hline$M$ & 5.66 & 5.00 & 6.08 & 5.89 & 5.91 & 5.59 & 59.63 & 12.98 & 64.87 \\
$S D$ & 0.99 & 1.77 & 1.15 & 1.24 & 1.06 & 1.16 & 46.01 & 7.37 & 27.96 \\
Min-Max & $1-7$ & $1-7$ & $1-7$ & $1-7$ & $1-7$ & $1-7$ & $0-359$ & $0-50$ & $0-100$ \\
Cronbach's $\alpha$ & .47 & -- & -- & -- & .48 & .72 & -- & -- & -- \\
& & & & & & & & & \\
\hline
\end{tabular}

Note. SI = situational interest.

$* p<.05 . * * p<.001$.

Correlations between all of the participants' variables are also presented in Table 1 . The intrinsic motivation scale presented a significant positive correlation with maintained situational interest (now referred to simply as situational interest). The participation variables were also positively correlated with each other. Correlations between intrinsic motivation scores and participation were not significant, while situational interest and participation were positively correlated. Intrinsic motivation, situational interest and both participation variables were significantly correlated with final grade, with quiz attempts being the strongest coefficient. When the items of the intrinsic motivation scale were analysed separately as single-items, they presented different relations with both participation and final grade (Table 1). Mastery approach was positively correlated to quiz attempts, while value beliefs was positively correlated to video hits. Both mastery approach and value beliefs were positively correlated with grade. Individual 
interest was significantly correlated with situational interest but not significantly correlated to participation or final grade.

A structural equation modelling analysis was conducted to investigate the relationship between intrinsic motivation, participation, situational interest, and performance using the proposed research model (see Figure 1). From the 862 participants still active during the last three weeks of the course, 68 were identified as multivariate outliers $(p<.05$ based on Mahalanobis distance), but upon closer inspection, they proved to be valid data points and were retained. There was evidence that both univariate and multivariate normality were violated for all variables $(p<.05$ in Shapiro-Wilk test, multivariate Kurtosis $=130.94)$. Therefore, the model was estimated with maximum likelihood estimation and tested using the Bollen-Stine bootstrap chi-square (Bollen \& Stine, 1992). The parameters estimates and standard errors were also adjusted using bootstrap (2,000 bootstrap samples, 95\% confidence interval; Mooney \& Duval, 1993). For the sample, there were no missing data. In the light of the skewness of the variables, transformations were applied. Analyses using transformed variables yielded similar results to analyses using the untransformed variables. Therefore, raw untransformed data were used to allow a more meaningful interpretation of results.

The proposed model with all possible paths between the variables presented a moderate fit, Bollen-Stine chi-square $\chi^{2}(8, n=862)=8.31, p=.001, \mathrm{RMSEA}=.06, \mathrm{CFI}=.98, \mathrm{CMIN} / \mathrm{DF}$ $=1.04, \mathrm{BIC}=163.85$. However, this model presented several non-significant paths. A good fit model (Figure 2) with only significant paths was then found, Bollen-Stine chi-square $\chi^{2}(12, n=$ $862)=12.43, p=.001, \mathrm{RMSEA}=.05, \mathrm{CFI}=.97, \mathrm{CMIN} / \mathrm{DF}=1.04, \mathrm{BIC}=143.58$. This model explained $27 \%$ of the variance in final grade. In relation to direct effects of this model, intrinsic motivation predicted video hits and situational interest. Final grade was predicted mainly by quiz attempts, and to a lesser extent by situational interest and video hits. For comparison purposes, a 
model considering only video hits and quiz attempts explained $26 \%$ of the variance in final grade.

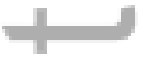

\section{[INSERT FIGURE 2 ABOUT HERE]}

Figure 2. Structural equation model with standardised beta scores showing the relationship between intrinsic motivation, participation, situational interest, and performance of persistent students in a MOOC. All paths are significant $(p<.05)$. Bollen-Stine chi-square $\chi^{2}(12, n=862)$

$$
=12.43, p=.001, \mathrm{RMSEA}=.05, \mathrm{CFI}=.97, \mathrm{CMIN} / \mathrm{DF}=1.04, \mathrm{BIC}=143.58 \text {. }
$$

The low alpha of the intrinsic motivation scale (.47), and the positive correlations of its different components with participation and final grade (Table 1) suggested further exploratory analysis considering each component as a separate predictor. The proposed model with all possible paths between the variables initially was over fitted; a number of paths were then dropped based on chi-square differences (Garson, 2012). The first model with adequate fit still presented some non-significant paths, Bollen-Stine chi-square $\chi^{2}(2, n=862)=1.84, p=.973$, RMSEA $=.00, \mathrm{CFI}=1.00, \mathrm{CMIN} / \mathrm{DF}=.92, \mathrm{BIC}=175.80$. The final model, which included only significant paths, fitted these data well, Bollen-Stine chi-square $\chi^{2}(7, n=862)=6.93, p=$ $.592, \mathrm{RMSEA}=.00, \mathrm{CFI}=1.00, \mathrm{CMIN} / \mathrm{DF}=.99, \mathrm{BIC}=147.44($ Figure 3$)$. This model explained $28 \%$ of the variance in final grade. In relation to the direct effects in this model, value beliefs predicted video hits, while mastery-approach goals predicted quiz attempts. All three of the general approach to course content variables directly predicted maintaining situational interest. For the participation variables, video hits directly predicted maintaining situational interest. The strongest predictor of final grade was quiz attempts, followed by positive direct 
effects from maintaining situational interest and video hits. Individual interest made a small negative predictive contribution to final grade.

\section{[INSERT FIGURE 3 ABOUT HERE]}

Figure 3. Structural equation model with standardised beta scores showing the relationship between motivation, participation, and performance of persistent students in a MOOC. All paths are significant $(p<.05)$. Bollen-Stine chi-square $\chi^{2}(7, n=862)=6.93, p=.592$, RMSEA $=.00$,

$$
\mathrm{CFI}=1.00, \mathrm{CMIN} / \mathrm{DF}=.99, \mathrm{BIC}=147.44
$$

To determine the significant indirect mediated effects in the model, bootstrapping analyses were used (Preacher \& Hayes, 2004; Preacher, Rucker, \& Hayes, 2007). In these analyses, 2,000 bootstrapped samples and their 95\% confidence intervals were used to test for mediation. Total effects (TE), direct effects (DE) and indirect effects (IE) were considered. Value beliefs had significant direct and indirect effects on situational interest, being partially mediated by video hits $(\mathrm{TE}=.452, p=.001 ; \mathrm{DE}=.441, p=.001 ; \mathrm{IE}=.011, p=.001)$. However, the impact of value beliefs on final grade was fully mediated by both situational interest $(\mathrm{TE}=$ $.090, p=.004 ; \mathrm{DE}=.032, p=.321, \mathrm{IE}=.058, p=.001)$ and video hits $(\mathrm{TE}=.047, p=.145 ; \mathrm{DE}$ $=.032, p=.320 ; \mathrm{IE}=.015, p=.001)$. The impact of individual interest on final grade was negative and partially mediated by situational interest $(\mathrm{TE}=-.061, p=.050 ; \mathrm{DE}=-.081, p=$ $.012 ; \mathrm{IE}=.021, p=.001)$. Mastery-approach had a direct effect $(.201, p=.001)$ on maintaining situational interest, with no mediation. Its impact on final grade, however, was fully mediated by both situational interest $(\mathrm{TE}=.084, p=.010 ; \mathrm{DE}=.059, p=.076 ; \mathrm{IE}=.026, p<.001)$ and quiz attempts $(\mathrm{TE}=.093, p=.015 ; \mathrm{DE}=.059, p=.071 ; \mathrm{IE}=.035, p=.022)$. Video hits had significant direct and indirect effects on final grade, being partially mediated by situational 
interest $(\mathrm{TE}=.127, p=.001 ; \mathrm{DE}=.112, p=.001 ; \mathrm{IE}=.015, p=.001)$. Quiz attempts had the strongest effect on final grade $(.475, p=.001)$, with no indirect or mediated effects.

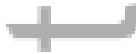

\section{Discussion}

This study examined how motivation and participation predicted performance from a $=1$ sample of students who persisted to the end of a MOOC, and demonstrated a significant set of paths linking motivation, participation and performance. Our results suggest that motivation is related to MOOC performance both directly and indirectly. Similarly, participation has both direct and indirect influences on performance. The influence of general motivation for learning on performance, such as value beliefs and mastery approach, is mediated by participation. While the influence of participation, such as video hits, is mediated by state-level motivation, such as situational interest.

The research presented in this article contributes to our understanding of some of the factors operating when persisting students engage with MOOCs. Number of quiz attempts was found to be the strongest predictor of final grade for the survey respondents. This is neither a surprising nor new finding; learning analytics and educational research has established that the more students engage with activities, the better they perform (e.g., Kizilcec, Piech, \& Schneider, 2013). However, when motivational variables are considered as antecedents to participation, our findings suggest that value beliefs and mastery approach differentially contributed to their participation with video lectures and quizzes. This indicates that the general motivation for learning students bring to the course influences their engagement with activities. Again, this is not new across to the educational literature, but what is important with these findings is that they relate to this relatively new mode of course delivery: MOOCs. 
An additional finding from this study was the crucial role state-level motivation plays as a mediator between intrinsic motivation and participation on the one hand, and performance on the other. Situational interest was the strongest motivational factor to predict performance, both directly and as a mediator for other variables. The level of students' situational interest maintained across the course in any learning environment is fundamentally contextual; that is, it depends on how well course activities and content focus and hold students' attention. As Hidi and Renninger (2006) have argued, situational interest is maintained by the interplay between the individual and a myriad of features within the learning environment. It should be noted that overall, in the current study students commenced the course with relatively high levels of individual interest, which does not necessarily guarantee that situational interest is maintained across the course. Although impractical in the current context of this MOOC, it is desirable to have immediate measures rather than a delayed measure of situational interest. One implication of this finding is that given the high level of interest with which participants approached this course, it is likely that aspects of MOOC design, for example, content and organisation of learning activities, structure and alignment of assignments and assessment tasks, production and presentation of resources and media, have impacted on how interest was maintained.

Understanding how situational interest can be triggered and maintained has been a central theme in the application of motivational research in educational settings (Ainley, 2010). Researchers such as Durik and Harackiewicz (2007) have found that learning activities designed to catch or trigger interest were more effective for students with low initial individual interest, and activities designed to hold or maintain interest were more effective for students with high initial individual interest. In our model, there was a small negative relationship between individual interest and final grade. After allowing for the positive relationship between situational interest, mastery-approach goals and both participation and performance, there was a 
tendency for individual interest to be associated with poorer grades. While not mirroring the Durik and Harackiewicz (2007) findings, our findings suggest that some students who come to a MOOC with high individual interest may either find the content does not match their expectations or have problems to self-regulate their learning, and they do not perform as well as might be predicted from their individual interest in the course topic.

The complex relationships both among motivation constructs and between participation and course performance, suggest when designing MOOC activities attention should be given to different conditions that might accommodate different levels of motivation. It has been well established in previous research that participation and motivation are highly correlated (see Pintrich, 2003 for review). Hence, the differences found in this research between respondents and non-respondents in their level of participation is likely to be related to differences in their level of motivation. Although general motivation for learning is a relatively stable orientation (Pintrich, 2003), there have been successful efforts to create classroom environments more favourable to adoption of mastery goals, and this has subsequently been associated with high levels of persistence (e.g., Blackwell, Trzesniewski, \& Dweck, 2007). However, it is worth noting that Greene (2013) did not find this pattern of results when trying to replicate Blackwell and colleagues' findings in a MOOC. The findings of our research suggest that MOOC design consider focusing on maintaining situational interest across the course, as it appears to be a key factor for performance of students who persist to the end of the course. In addition, there are potentially different effects for students who commence with different levels of individual interest in course content (Harackiewicz, Durik, Barron, Linnenbrick-Garcia, \& Tauer, 2008; Hidi \& Harackiewicz, 2000; Kennedy, 2004). It is worth noting that one of the requirements for participation in the original cMOOC was an interest in artificial intelligence (Daniel, 2012; Yuan \& Powell, 2013). Given MOOCs attract such a diversity of learners-learners with different 
backgrounds, reasons for enrolling, levels of self-regulation skills and prior knowledgeunderstanding more of the dynamics of student motivation as students engage with MOOC content would seem to be a particularly fruitful direction for further research and development.

While the results of this study have shown some promising findings, and have provided some insight into how variables representing motivation and participation function to contribute to course grades for students who persisted in a MOOC, they must be seen as preliminary. The application of traditional motivation measures developed using mainly undergraduates and adolescents participants did not present the same levels of reliability when applied to the more varied MOOC population. Further studies should take this measurement issue into consideration, and also consider measuring motivation at various points in time distributed across the course, especially with regards to situational interest. Thereby providing clearer insights into how learning design, participation and motivation contribute to performance.

Generalisation of the findings of this study is limited by three factors. First, respondents were a limited sample of MOOCs participants, representing $12.3 \%$ of students who persisted on the course. It is not clear why these students chose to respond to the online questionnaire. However, we do know they presented significantly different levels of participation and performance in the MOOC studied, with the most engaged and successful students completing the questionnaire. The fact that we used a post-course survey might have contributed to this, and it may be prudent in the future to embed questionnaires at various stages of the course. It may also be necessary to develop questionnaires that reliably measure constructs with fewer items to encourage students' research participation. Second, there were differences between respondents and non-respondents, indicating that generalisation of this model might be restricted to students who completed the MOOC and who had high levels of participation and performance. Third, the sample was drawn from only one MOOC, and so generalisations to other MOOCs is not 
recommended. Nonetheless, this research does provide preliminary insight into how established models of educational research can be applied to better understand how motivation and participation are associated with performance in the emerging online learning context of MOOCs.

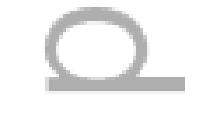

$=$

1

\section{Conclusion}

In summary, this research investigated how persistent students' motivation and participation is likely to influence their performance in a MOOC. Findings indicated that the strongest predictor of performance was participation, and motivation added to the prediction of performance. Motivation influenced and was influenced by students' participation during course. Moreover, situational interest played a crucial role in mediating the impact of both general motivation for learning and participation on performance. These results suggest that it might be useful to use motivation and participation measures to tailor the learning environment.

Recommended future research includes the development of innovative and reliable measurement solutions of motivational constructs in MOOCs; better understanding of how specific MOOC design and features impact students' motivation, participation and performance; and further investigation of how the diversity of MOOC students (e.g., learners with different backgrounds, reasons for enrolling, levels of self-regulation skills and prior knowledge) is related to their statelevel motivation across the course.

\section{Acknowledgements}

We would like to thank the Principles of Macroeconomics MOOC coordinator Nils Olekalns for partnering with us. Also, we would like to thank Colin Tatham and Sadia Nawaz for retrieving the data from the Coursera platform. This research is part of Paula de Barba's PhD 
program, which is funded by The University of Melbourne, the Institute for a Broadband-

Enabled Society, and the Science of Learning Research Centre, Australia.

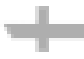

\section{References}

Ainley, M. D. (2006). Connecting with learning: Motivation, affect and cognition in interest

processes. Educational Psychology Review, 18(4), 391-405. doi:10.1007/s10648-006-

9033-0

Ainley, M. D. (2010). Interest in the dynamics of task behavior: Processes that link person and task in effective learning. In T. C. Urdan \& S. A. Karabenick (Eds.), The decade ahead: Theoretical perspectives on motivation and achievement Volume 16A: Advances in Motivation and Achievement (pp. 235-264). Bingley, UK: Emerald.

Ainley, M. D., \& Patrick, L. (2006). Measuring self-regulated learning processes through tracking patterns of student interaction with achievement activities. Educational Psychology Review, 18(3), 267-286. doi:10.1007/s10648-006-9018-z

Ames, C. (1992). Classrooms: Goals, structures, and student motivation. Journal of Educational Psychology, 84(3), 261-271. doi:10.1037/0022-0663.84.3.261

Belenky, D. M., \& Nokes-Malach, T. J. (2012). Motivation and transfer: The role of masteryapproach goals in preparation for future learning. Journal of the Learning Sciences, 21(3), 399-432. doi:10.1080/10508406.2011.651232

Blackwell, L. S., Trzesniewski, K. H., \& Dweck, C. S. (2007). Implicit theories of intelligence predict achievement across an adolescent transition: A longitudinal study and an intervention. Child Development, 78(1), 246-263. doi:10.1111/j.1467-8624.2007.00995.x 
Bollen, K. A., \& Stine, R. A. (1992). Bootstrapping goodness-of-fit measures in structural equation models. Sociological Methods and Research, 21, 205-229. doi:10.1177/0049124192021002004

Breslow, L., Pritchard, D. E., DeBoer, J., Stump, G. S., Ho, A. D., \& Seaton, D. T. (2013). Studying learning in the worldwide classroom: Research into edX's first MOOC. $=$ Research \& Practice in Assessment, 8, 13-25. Retrieved from http://mooc.pku.edu.cn/source/resource/01.pdf

Christensen, G., Steinmetz, A., Alcorn, B., Bennett, A., Woods, D., \& Emanuel, E. J. (2013). The MOOC phenomenon: Who takes massive open online courses and why? Social Science Research Network. doi:10.2139/ssrn.2350964

Clow, D. (2013). MOOCs and the funnel of participation. In D. Suthers, K. Verbert, E. Duval, \& X. Ochoa (Eds.), Proceedings of the Third International Conference on Learning Analytics and Knowledge (pp. 185-189). New York, NY: Association for Computing Machinery. doi:10.1145/2460296.2460332

Daniel, J. (2012). Making sense of MOOCs: Musings in a maze of myth, paradox and possibility. Journal of Interactive Media in Education, 3, 1-20. doi:10.5334/2012-18

De Barba, P. (2015). Achievement motivation and autonomous learning in online environments. $\mathrm{PhD}$ thesis in preparation, The University of Melbourne, Australia.

Durik, A. M., \& Harackiewicz, J. M. (2007). Different strokes for different folks: How individual interest moderates the effects of situational factors on task interest. Journal of Educational Psychology, 99(3), 597-610. doi:10.1037/0022-0663.99.3.597

Dweck, C. S. (1986). Motivational processes affecting learning. American Psychologist, 41(10), 1040-1048. doi:10.1037/0003-066X.41.10.1040 
Eccles, J. S., \& Wigfield, A. (2002). Motivational beliefs, values, and goals. Annual Review of Psychology, 53(1), 109-132. doi:10.1146/annurev.psych.53.100901.135153

Eccles, J. S., Wigfield, A., \& Schiefele, U. (1998). Motivation to succeed. In W. Damon \& N.

Eisenberg (Eds.), Handbook of child psychology: Vol. 3. Social, emotional, and personality development (pp. 1017-1095). New York, NY: Wiley.

$=$

Elliot, A. J., \& McGregor, H. A., (2001). A $2 \times 2$ achievement goal framework. Journal of Personality and Social Psychology, 80(3), 501-519. doi:10.1037/0022-3514.80.3.501

Garson, G. D. (2012). Structural Equation Modeling. Asheboro, NC: Statistical Associates Publishers.

Gogol, K., Brunner, M., Goetz, T., Martin, R., Ugen, S., Keller, U., Fischbach, A., \& Prenzel, F. (2014). 'My questionnaire is too long!' The assessments of motivational-affective constructs with three-item and single-item measures. Contemporary Educational Psychology, 39(3), 188-205. doi:10.1016/j.cedpsych.2014.04.002

Greene, D. (2013). Learning analytics for smarter psychological interventions. Retrieved from http://www.moocresearch.com/wp-content/uploads/2014/06/C9337_GREEN_MOOCResearch-InitiativeGreene9337.pdf

Harackiewicz, J. M., Durik, A. M., Barron, K. E., Linnenbrink-Garcia, L., \& Tauer, J. M. (2008).

The role of achievement goals in the development of interest: Reciprocal relations between achievement goals, interest, and performance. Journal of Educational Psychology, 100(1), 105-122. doi:10.1037/0022-0663.100.1.105

Hart, C. (2012). Factors associated with student persistence in an online program of study: a review of the literature. Journal of Interactive Online Learning, 11(1), 19-42. Retrieved from http://www.ncolr.org/jiol/issues/pdf/11.1.2.pdf 
Hidi, S. (1990). Interest and its contribution as a mental resource for learning. Review of Educational Research, 60(4), 549-571. doi:10.3102/00346543060004549

Hidi, S., \& Harackiewicz, J. M. (2000). Motivating the academically unmotivated: A critical issue for the 21st century. Review of Educational Research, 70(2), 151-179. doi:10.3102/00346543070002151

Hidi, S., \& Renninger, K. A. (2006). The four-phase model of interest development. Educational Psychologist, 41(2), 111-127. doi:10.1207/s15326985ep4102_4

Hulleman, C. S. (2007). The role of utility value in the development of interest and achievement. Unpublished doctoral dissertation, University of Wisconsin, Madison, WI.

Kennedy, G. E. (2004). Promoting cognition in multimedia interactivity research. Journal of Interactive Learning Research, 15(1), 43-61.

Kim, J., Guo, P. J., Seaton, D. T., Mitros, P., Gajos, K. Z., \& Miller, R. C. (2014). Understanding in-video dropouts and interaction peaks in online lecture videos. In M. Sahami, A. Fox, M. A. Hearst, \& M. T. H. Chi. (Eds.), Proceedings of the First ACM Learning@ Scale conference (pp. 31-40). New York, NY: Association for Computing Machinery. doi: $10.1145 / 2556325.2566237$

Kizilcec, R. F., Piech, C., \& Schneider E. (2013). Deconstructing disengagement: Analyzing learner subpopulations in massive open online courses. In D. Suthers, K. Verbert, E. Duval, \& X. Ochoa (Eds.), Proceedings of the Third International Conference on Learning Analytics and Knowledge (pp. 170-179). New York, NY: Association for Computing Machinery. doi:10.1145/2460296.2460330

Littlejohn, A. (2013). Understanding Massive Open Online Courses. Caledonian Academy Glasgow, Caledonian University, UK. Retrieved from 
http://cemca.org.in/ckfinder/userfiles/files/EdTech\%20Notes\%202_Littlejohn_final_1Jun e2013.pdf

Liyanagunawardena, T. R., Adams, A. A., \& Williams, S. A. (2013). MOOCs: A Systematic Study of the Published Literature 2008-2012. The International Review of Research in Open and Distance Learning, 14(3). Retrieved from http://www.irrodl.org

McGregor, H. A., \& Elliot, A. J. (2002). Achievement goals as predictors of achievementrelevant processes prior to task engagement. Journal of Educational Psychology, 94(2), 381-394. doi:10.1037/0022-0663.94.2.381

Milligan, C., Littlejohn, A., \& Margaryan, A. (2013). Patterns of engagement in connectivist MOOCs. MERLOT Journal of Online Learning and Teaching, 9(2). Retrieved from http://jolt.merlot.org

MOOCs@Edinburgh Group. (2013). MOOCs@Edinburgh Report \#1. Retrieved from https://www.era.lib.ed.ac.uk/bitstream/1842/6683/1/Edinburgh\%20MOOCs\%20Report\% 202013\%20\%231.pdf

Mooney, C. Z., \& Duval, R. D. (1993). Bootstrapping: A nonparametric approach to statistical inference. Newbury Park, CA: Sage.

Nicholls, J. G. (1984). Achievement motivation: Conceptions of ability, subjective experience, task choice, and performance. Psychological Review, 91(3), 328-346. doi:10.1037/0033$295 \times .91 .3 .328$

Preacher, K.J., \& Hayes, A. F. (2004). SPSS and SAS procedures for estimating indirect effects in simple mediation models. Behavior Research Methods, Instruments \& Computers, 36(4), 717-731. doi:10.3758/BF03206553 
Preacher, K. J., Rucker, D. D., \& Hayes, A. F. (2007). Addressing moderated mediation hypotheses: Theory, methods, and prescriptions. Multivariate Behavioral Research, 42(1), 185-227. doi:10.1080/00273170701341316

Pintrich, P. R. (2000). Multiple goals, multiple pathways: The role of goal orientation in learning and achievement. Journal of Educational Psychology, 92(3), 544-555. doi:10.1037/0022-

= 0663.92.3.544

Pintrich, P. R. (2003). A motivational science perspective on the role of student motivation in learning and teaching contexts. Journal of Educational Psychology, 95(4), 667-686. doi:10.1037/0022-0663.95.4.667

Pintrich, P. R., Smith, D. A., García, T., \& McKeachie, W. J. (1991). A manual for the use of the Motivated Strategies for Learning Questionnaire (MSLQ). Ann Arbor, MI: National Centre For Research to Improve Postsecondary Teaching and Learning.

Rayyan, S., Seaton, D. T., Belcher, J., Pritchard, D. E., \& Chuang, I. (2013). Participation and Performance In 8.02x Electricity And Magnetism: The First Physics MOOC From MITx. In P. V. Engelhardt, A. D. Churukian, \& D. L. Jones (Eds.), Proceedings of the 2013 Physics Education Research Conference (pp. 289-292). College Park, MD: American Association of Physics Teachers. doi:10.1119/perc.2013.pr.060

Renninger, K. A. (1990). Children's play interests, representation, and activity. In R. Fivush \& K. Hudson (Eds.), Knowing and remembering in young children (pp. 127-165). New York, NY: Cambridge University Press.

Rotgans, J. I., \& Schmidt, H. G. (2011). Situational interest and academic achievement in the active-learning classroom. Learning and Instruction, 21(1), 58-67. doi:10.1016/j.learninstruc.2009.11.001 
Senko, C., Hulleman, C. S., \& Harackiewicz, J. M. (2011). Achievement goal theory at the crossroads: Old controversies, current challenges, and new directions. Educational Psychologist, 46(1), 26-47. doi:10.1080/00461520.2011.538646

Siemens, G. (2005). Connectivism: A learning theory for the digital age. International Journal of Instructional Technology and Distance Learning, 2(1). Retrieved from

http://www.itdl.org

Sun, J. C. Y., \& Rueda, R. (2012). Situational interest, computer self- efficacy and selfregulation: Their impact on student engagement in distance education. British Journal of Educational Technology, 43(2), 191-204. doi:10.1111/j.1467-8535.2010.01157.x

Vallerand, R. J., Fortier, M. S., \& Guay, F. (1997). Self-determination and persistence in a reallife setting: toward a motivational model of high school dropout. Journal of Personality and Social Psychology, 72(5), 1161-1175. doi:10.1037/0022-3514.72.5.1161

Vanthournout, G., Gijbels, D., Coertjens, L., Donche, V., \& Van Petegem, P. (2012). Students' persistence and academic success in a first-year professional bachelor program: The influence of students' learning strategies and academic motivation. Education Research International, 2012, 1-10. doi:10.1155/2012/152747

Wanous, J. P., Reichers, A. E., \& Hudy, M. J. (1997). Overall job satisfaction: how good are single-item measures? Journal of Applied Psychology, 82(2), 247-252. doi:10.1037/0021-9010.82.2.247

Wigfield, A., \& Cambria, J. (2010). Students' achievement values, goal orientations, and interest: Definitions, development, and relations to achievement outcomes. Developmental Review, 30(1), 1-35. doi:10.1016/j.dr.2009.12.001

Wigfield, A., \& Eccles, J. S. (1992). The development of achievement task values: A theoretical analysis. Developmental Review, 12(3), 265-310. doi:10.1016/0273-2297(92)90011-P 
Wigfield, A., \& Eccles, J. S. (2000). Expectancy-value theory of achievement motivation. Contemporary Educational Psychology, 25(1), 68-81. doi:10.1006/ceps.1999.1015

Yang, C. C., Tsai, I., Kim, B., Cho, M. H., \& Laffey, J. M. (2006). Exploring the relationships between students' academic motivation and social ability in online learning

$=$ environments. The Internet and Higher Education, 9(4), 277-286.

doi:10.1016/j.iheduc.2006.08.002

Yuan, L., \& Powell, S. (2013). MOOCs and open education: Implications for higher education [White paper]. Bolton, UK: Joint Information Systems Committee, Centre for Educational Technology and Interoperability Standards. Retrieved from http://publications.cetis.ac.uk/2013/667
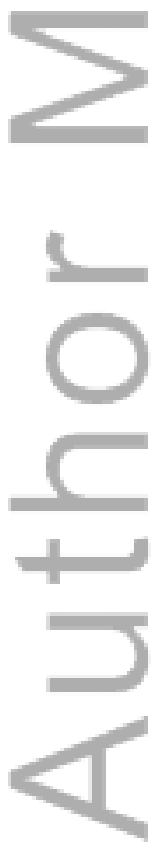


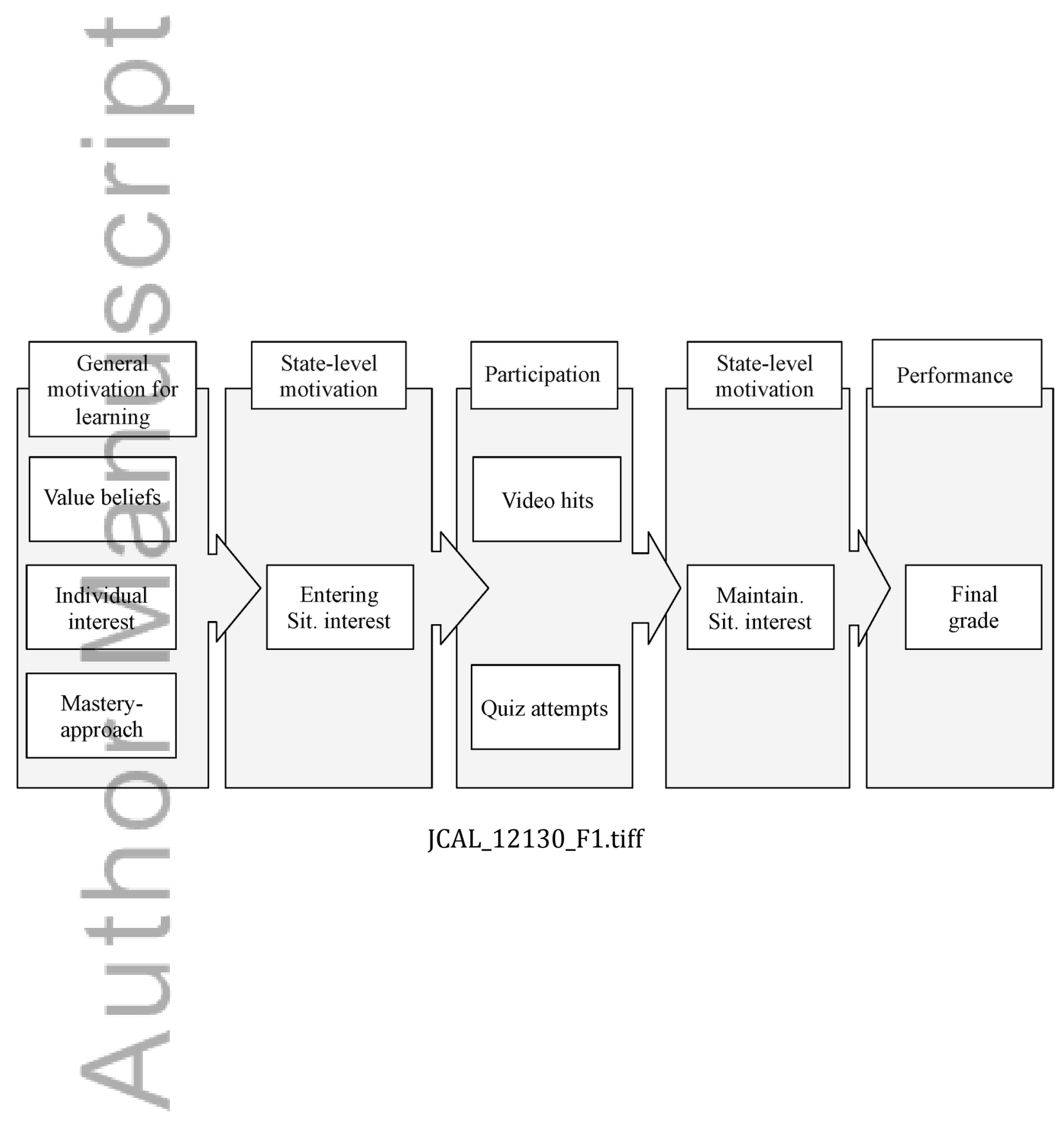

This article is protected by copyright. All rights reserved. 


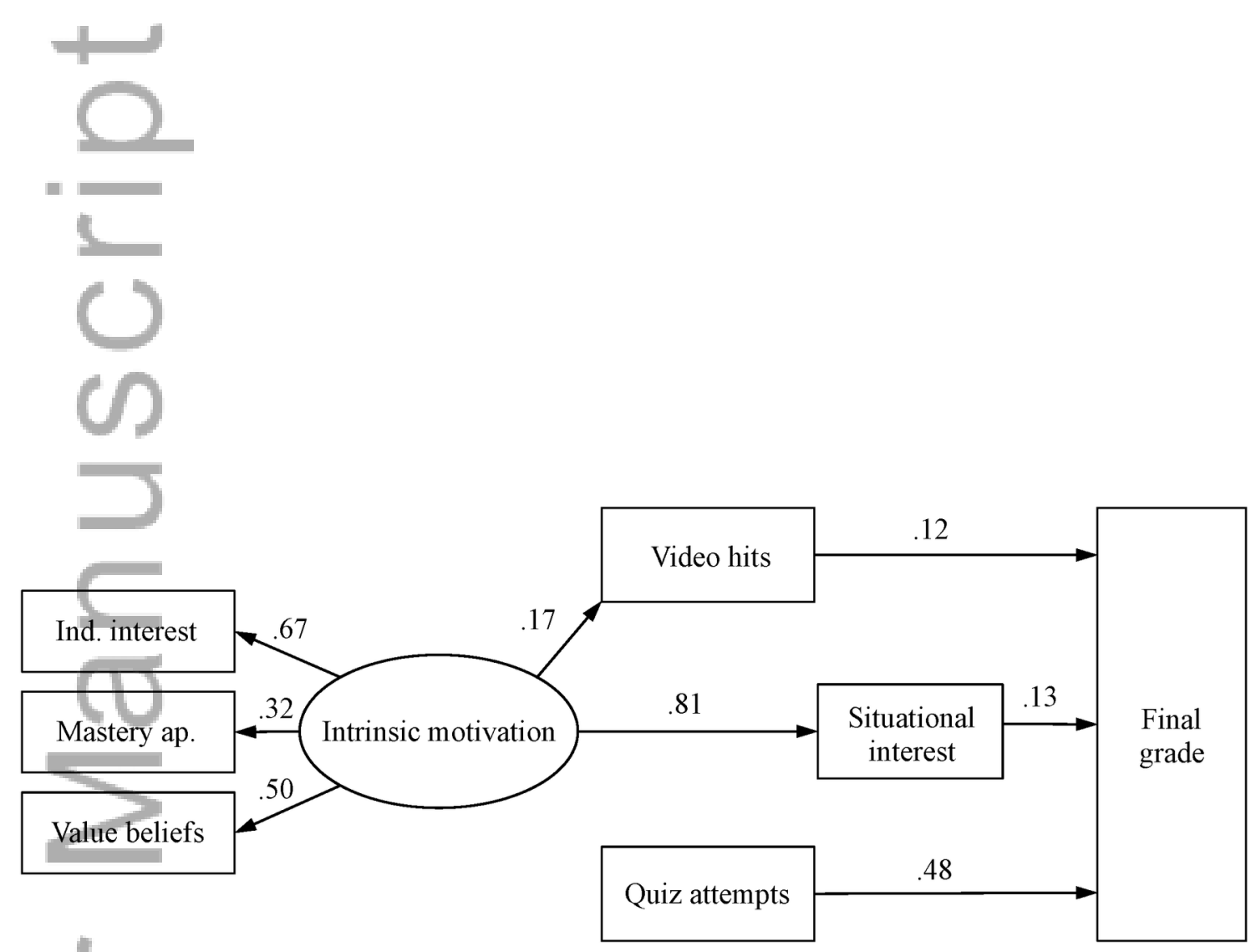

JCAL_12130_F2.tiff

This article is protected by copyright. All rights reserved. 


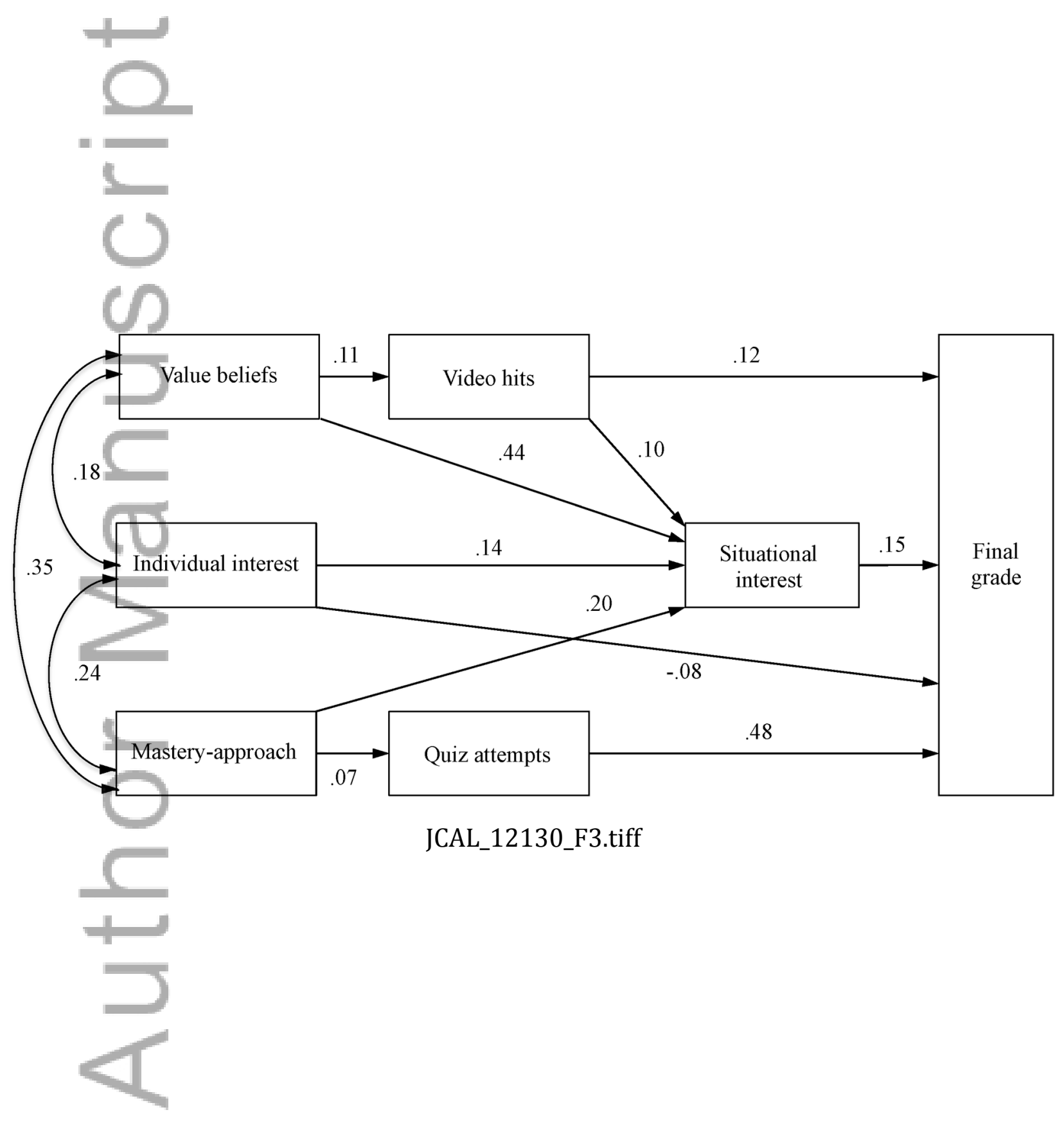

This article is protected by copyright. All rights reserved. 


\section{University Library}

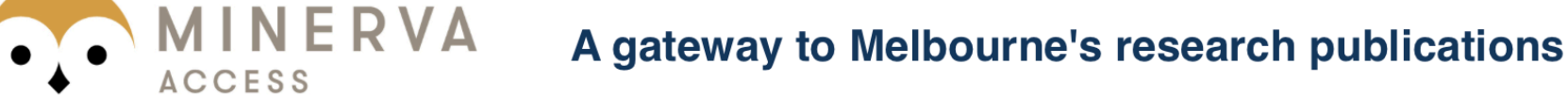

Minerva Access is the Institutional Repository of The University of Melbourne

Author/s:

DE BARBA, P;Kennedy, G;Ainley, M

Title:

The role of students' motivation and participation in predicting performance in a MOOC Motivation and participation in MOOCs

Date:

2016

Citation:

DE BARBA, P., Kennedy, G. \& Ainley, M. (2016). The role of students' motivation and participation in predicting performance in a MOOC Motivation and participation in MOOCs. Journal of Computer Assisted Learning, 32 (3), pp.218-231. https://doi.org/10.1111/ jcal. 12130.

Persistent Link:

http://hdl.handle.net/11343/290768 